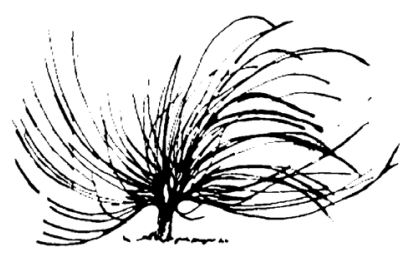

\title{
Formación universitaria en Artes Plásticas: Del ejercicio de la copia a una propuesta pedagógica para la emancipación
}

\author{
Beatriz Quesada Calderón ${ }^{1}$ \\ Universidad de Costa Rica \\ Costa Rica \\ maria.quesadacalderon@ucr.ac.cr
}

\begin{abstract}
Resumen
El siguiente ensayo reflexiona, a partir de la experiencia personal y profesional de la autora, acerca de la formación académica y profesional en el área de las Artes Plásticas, en la educación superior. Para esto, se contemplan aspectos del contexto social, político, económico e institucional en el que se enmarca dicha experiencia. El abordaje se realiza desde la pedagogía universitaria, lo que permite problematizar la manera en que se constituye el currículo y desarrolla la docencia, en la educación artística universitaria. Además, se busca proponer alternativas pedagógicas críticas que lleven a una educación artística decolonial y emancipatoria, que promueva mayor involucramiento del estudiantado en el proceso educativo, así como el replanteamiento de los posicionamientos epistemológicos y pedagógicos actuales, desde los que sustenta la formación universitaria en las artes plásticas.
\end{abstract}

\section{(c) (1) $\Theta \Theta$}

http://dx.doi.org/10.15359/rep.esp-21.2

1 Labora en la Universidad de Costa Rica desde el año 2015, en donde se desempeña como asesora curricular en el Programa de Desarrollo Curricular del Centro de Evaluación Académica. Posee una Licenciatura en Artes Plásticas con énfasis en Pintura de la UCR, y actualmente cursa la Maestría en Educación con énfasis en Pedagogía Universitaria de la Universidad Nacional de Costa Rica. 
Palabras clave: Pedagogía, artes plásticas, docencia, currículum, emancipación, educación superior.

\begin{abstract}
This essay reflects, from the personal and professional experience of the author, on the academic and professional training in the area of Arts in the higher education. For this, aspects of the social, political, economic and institutional context in which the experience is framed are contemplated. The approach is carried out from University Pedagogy, which allows to problematize the way in which the curriculum is constituted and develops the teaching in the university arts education. In addition, this essay to propose critical pedagogical alternatives, leading to a decolonial and emancipatory artistic education, which promotes greater involvement of students in the educational process, as well as in the rethinking of current epistemological and pedagogical positions, on which university arts education is based.
\end{abstract}

Keywords: pedagogy, arts, teaching, curriculum, emancipation, higher education.

\title{
I. Introducción
}

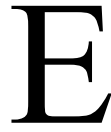

1 presente escrito parte de una reflexión en torno al proceso de enseñanza y aprendizaje que se da en el área de las Artes Plásticas a nivel de educación superior. Se sitúa, específicamente, en la experiencia personal, académica y profesional de la autora, en la etapa como estudiante de Pintura en la Universidad de Costa Rica y su experiencia actual como asesora curricular -en la misma institución- y el proceso de reflexión de su praxis pedagógica como estudiante de la Maestría en Educación con énfasis en Pedagogía Universitaria en la Universidad Nacional.

Los apartados que se desarrollan en este documento tratan temas relacionados con la docencia, la pedagogía y el currículum en la educación superior. Asimismo, a partir de la reflexión personal, se plantea la necesidad de trazar posibles rutas hacia la transformación, a través del cuestionamiento y la problematización de la educación artística universitaria. 
Este ensayo contempla, en primer lugar, la experiencia educativa personal en la carrera de Artes Plásticas con énfasis en Pintura en la Universidad de Costa Rica (UCR). Por este motivo, se inicia con una contextualización social, institucional e histórica de las carreras de Artes Plásticas.

Seguidamente, se aborda desde la experiencia como estudiante, el posicionamiento pedagógico y epistemológico de la formación académica en Artes Plásticas. Se analiza la conformación del currículum en las carreras de Artes Plásticas, desde el proceso de asesoría curricular; para, luego, reflexionar sobre la necesidad de la articulación entre pedagogía y currículum en una propuesta educativa, como lo es una carrera universitaria.

Finalmente, se plantea una propuesta de abordaje pedagógico para la emancipación y la transformación desde el currículum y la docencia universitaria en el área de las Artes Plásticas.

\section{Enseñanza de las Artes Plásticas en la Universidad de Costa Rica: trazando un breve recorrido histórico y epistemológico}

Para iniciar, es preciso mencionar que la experiencia pedagógica que atañe en este documento se ubica dentro de una de las cinco universidades públicas del país: la Universidad de Costa Rica (UCR). En cuanto a dicha institución, la propia UCR se define en el artículo 1 del Estatuto Orgánico como:

una institución de educación superior y cultura, autónoma constitucionalmente y democrática, constituida por una comunidad de profesores y profesoras, estudiantes, funcionarias y funcionarios administrativos, dedicada a la enseñanza, la investigación, la acción social, el estudio, la meditación, la creación artística y la difusión del conocimiento. (UCR, 1974, p. 1)

Asimismo, como parte del contexto de la experiencia, es necesario reflexionar acerca de la situación social en que se encuentra inmersa la institución, pues pese a ser una universidad pública y autónoma, como bien se afirma en su estatuto, en la actualidad, se encuentra en un ambiente político y económico en el que, debido a presiones externas, se cuestionan los recursos invertidos en la formación de personas profesionales. 
Tomando en cuenta esta situación particular, se considera pertinente traer a colación lo expresado por De Sousa (2007) en relación con la pérdida de prioridad de la educación y con la crisis institucional que sufren las universidades públicas que se remonta a la década de los años 80 :

La pérdida de prioridad de la universidad pública en las políticas públicas del Estado fue, ante todo, el resultado de la pérdida general de prioridad de las políticas sociales (educación, salud, seguridad social) inducida por el modelo de desarrollo económico conocido como neoliberalismo o globalización neoliberal, que se impuso internacionalmente a partir de la década de los 80. (p. 26)

Esta crisis causada por las presiones ejercidas por diferentes grupos hegemónicos, no es una realidad exclusiva de Costa Rica, sino que también se traslada al resto de América Latina. Por ejemplo, la Universidad Nacional Autónoma de México (UNAM) también ha experimentado estas presiones que coartan la libertad de cátedra y pensamiento, tal como lo expresa Saxe-Fernández (2006):

hoy en día la institución universitaria de mayor envergadura en América Latina, está sometida, junto con todo el sistema de educación media superior y superior de la región, a un ataque sistemático de sus fundamentos y de tradición de libertad de cátedra y de investigación humanista y de la cátedra e investigación desinteresada que caracterizan a la Universidad clásica, están siendo puestos en la picota, no por las "exigencias del mercado" o de una globalización en abstracto, sino, específicamente, por el Banco Mundial (BM) y los poderosos intereses domésticos e internacionales que se articulan desde ese centro institucional de poder imperial. (p. 5)

Frente a este panorama en el que se exige a las universidades estatales responder a las diferentes demandas -de índole económica, principalmente-, es posible preguntarse: ¿con qué propósito una universidad pública costarricense invierte fondos en la formación artística?, ¿para qué sirven las artes en la sociedad actual?, ¿qué papel desempeñan los artistas y las artistas?, ¿cuál es el aporte de las artes en la economía del país? 
En este sentido, la incorporación de la formación académica-profesional en artes en la UCR se justifica desde los mismos propósitos de la institución, mencionados en el artículo 5 del Estatuto Orgánico, específicamente en los incisos $d$ y e, en los que se incluye el desarrollo de las artes:

d) Contribuir al progreso de las ciencias, las artes, las humanidades y las tecnologías, reafirmando su interrelación y aplicándolas al conocimiento de la realidad costarricense y de la comunidad internacional.

e) Formar personal idóneo que se dedique a la enseñanza, las humanidades, las ciencias, la tecnología, las artes y las letras, para que participe eficazmente en el desarrollo del sistema de educación costarricense. (UCR, 1974, p. 2)

En consideración a estos propósitos y como parte de la labor ejercida como asesora curricular, al realizarse el diseño de una carrera universitaria, se debe tener claridad sobre los objetivos de la formación que se brinda y considerar los aportes, no solamente en términos económicos, sino también sociales y culturales, así como el impacto de la formación académica-profesional en la sociedad. Además, se debe considerar que los diseños curriculares deben ir en concordancia con los principios institucionales de una formación académica y profesional humanista -como lo es la UCR- cuyo compromiso recae en que las personas egresadas sean agentes transformadores de la realidad social.

Por otro lado, también es necesario tomar en cuenta que el arte como área de conocimiento no está exento a convertirse en un objeto más de consumo; no obstante, este tiene el potencial para crear conciencia, sensibilizar a las personas y lograr transformaciones en la sociedad. Por lo tanto, la formación académica profesional en esta área contempla, en el perfil académico de salida, la dimensión ética del arte.

Con base en lo anterior y como parte del análisis del contexto, es necesario remontar a los inicios históricos de la enseñanza de las Artes Plásticas en la UCR, para así dilucidar desde cuáles posicionamientos epistemológicos y desde cuál pedagogía inicia la educación artística en esta institución. 
La formación académica en artes se empieza a brindar en la UCR en la década de 1940, al crearse la universidad. A partir de este hecho, se asumen las escuelas y facultades independientes, entre ellas, la Escuela Nacional de Bellas Artes, fundada en Costa Rica en el año 1897, a cargo del pintor español Tomás Povedano de Arcos.

Al pasar a formar parte de la UCR, la Escuela Nacional de Be1las Artes se transforma en la Facultad de Bellas Artes. Posteriormente, en 1972, la Facultad de Bellas Artes amplía las áreas de formación artística y se subdivide en tres escuelas: la Escuela de Artes Plásticas (EAP), la Escuela de Artes Musicales (EAM) y la Escuela de Artes Dramáticas (EAD). Por tanto, la EAP se constituye como una de las unidades académicas de mayor antigüedad de la institución, con casi 122 años de existencia.

Ahora bien, en cuanto al posicionamiento epistemológico y pedagógico de la educación artística, cabe mencionar un antecedente particular del que aún se conservan ciertos rasgos. Este antecedente se evidencia en la forma en que, a partir los inicios de la Escuela Nacional de Bellas Artes -finales del siglo XIX- se enseñó a dibujar, pintar, esculpir, diseñar, modelar, a través de la implantación de un modelo de enseñanza europeo: el método Julien, tal y como lo afirma Sánchez (2016):

Desde el principio de la Escuela y para el desarrollo de las lecciones, se importa desde Francia la colección más antigua de la Universidad de Costa Rica y que consta de dos porciones: la Colección de vaciados en yeso y la Colección de litografías del Método Julien. (p. 5)

Esta colección de yesos y litografías constituye un método didáctico para la enseñanza del dibujo, desarrollado por el dibujante y pintor francés Bernard-Romain Julien. Estas láminas y vaciados en yeso eran un modelo para la enseñanza del dibujo académico, a través de la observación y la copia a mano alzada. En cuanto a esta manera específica de enseñar, se puede observar el predominio de un enfoque conductista, en el que la persona docente demuestra y el o la estudiante imita, copia y repite hasta llegar a la perfección.

En apariencia, este casi insignificante hecho evidencia no solo un posicionamiento pedagógico, sino también un posicionamiento epistemológico, herencia de la modernidad europea que acompaña los 
procesos de civilización de las colonias, en la que se implantan maneras específicas de ver el mundo, como lo afirma Martínez (2015):

Debemos estar claros que cada etapa de colonialidad ha tenido un sustento filosófico específico con el que se legitimó cada intromisión colonial. Cada una de las tres etapas ha sido justificada a partir de escuelas filosóficas que reditúan legitimidad a cambio de homogeneidad como paradigma de conocimiento: es el caso de la escolástica en la primera colonialidad, y la racionalidad en la segunda. En el tercer periodo la colonialidad ha variado en forma y fondo: los tipos de invasión ahora se propagan como formas culturales y no solamente políticas y económicas, como por ejemplo la intrusión de representaciones pictóricas en los medios masivos de comunicación ... (p. 21)

Los posicionamientos mencionados por Martínez (2015) se conservan hasta la fecha en la formación en artes plásticas, pues el enfoque academicista que se constata en el currículum actual está conformado por una serie de cursos de dibujo académico, anatomía humana -enseñada bajo los cánones de representación griegos-, cursos de historia del arte -en su mayoría occidental-, montaje de exhibiciones en galerías y museos, entre otros aspectos, que reproducen la visión de mundo de la modernidad europea.

En la actualidad, la Escuela de Artes Plásticas ofrece tres carreras: Bachillerato y Licenciatura en Historia del Arte, Bachillerato y Licenciatura Diseño Gráfico y Bachillerato y Licenciatura en Diseño Plástico -conformado por los énfasis de Diseño Escultórico, Diseño Cerámico, Diseño de la Estampa y Diseño Pictórico-. El plan de estudios actual de estas carreras data del año 2008; a partir de junio del 2017, este se encuentra en un proceso de revisión y actualización curricular.

Con base en lo anterior, la actual transformación de los planes de estudio representa una oportunidad en la que conviene pensar y repensar los objetivos de la formación artística actual que se desarrolla en la UCR y reflexionar en torno a las siguientes preguntas: ¿sigue vigente la visión de la formación artística bajo estos modelos europeos?, ¿desde qué posicionamiento epistemológico y pedagógico se da la actual enseñanza de las Artes Plásticas en la UCR?, ¿qué papel juega el arte latinoamericano dentro del currículo oficial? Estas preguntas dan pie a la posibilidad de 
replantear la visión pedagógica y curricular, con miras a la transformación del cómo se percibe, enseña, produce y consume -no solo desde el punto de vista económico- el arte en la sociedad costarricense.

Además, aunque la pertinencia académica y social de las artes plásticas en la UCR es más que evidente, pues se expresa desde los principios orientadores del Estatuto Orgánico, este hecho no exime a la Universidad, ni a la Unidad Académica de preocuparse por mantener una oferta académica actualizada, acorde con las necesidades sociales, económicas y culturales del país. Desde la normativa institucional, como lo son las "Políticas y Normas para la Actualización de planes de estudio" de la Vicerrectoría de Docencia, se establece que "cada tres años se debe evaluar, sistemática e integralmente, el desarrollo de los planes de estudio, bajo la responsabilidad del director de la unidad académica" (Vicerrectoría de Docencia, 1995, p. 24), tarea que se reafirma en el Plan Estratégico Institucional 2013-2017².

Asimismo, para lograr una oferta acorde con las necesidades sociales y con los avances en el conocimiento se debe realizar procesos de indagación y consulta, como se expresa en el documento "Políticas y Normas para la Actualización de planes de estudio", específicamente en la norma 5.4 que expresa: "se debe posibilitar la participación de distintos sectores en la evaluación de las carreras, tales como representantes de los Colegios Profesionales, del sector productivo y empresarial, graduados, estudiantes, profesores, etc" (Vicerrectoría de Docencia, 1995, p. 23).

A partir de estos antecedentes, se plantea una propuesta pedagógica y curricular que fortalezca la formación académica y profesional en las artes visuales; de manera que se amplíe la formación de artistas en una universidad latinoamericana, como lo es la UCR, desde un posicionamiento epistemológico crítico y transformador.

\section{Partir de la experiencia vivida: lo que se aprende en una escuela de Arte}

Para el desarrollo de este apartado es necesario apelar a la experiencia personal, como graduada de la Escuela de Artes Plásticas, pues esta permite analizar desde un posicionamiento crítico, fundamentado desde la teoría, la vivencia del proceso formativo.

2 Esta meta también es contemplada en la Ampliación del plan estratégico institucional 2018-2020. 
Desde niña escuchaba a mis familiares decir iQué artista! o iQué curiosa! ... es que tiene el don... Estas afirmaciones me hacían sentir de alguna manera especial, pues efectivamente creía que tenía un don; me gustaba dibujar, lo disfrutaba y, además, lo hacía bien. Mi madre decidió llevarme a cursos libres de pintura, desde los 10 años de edad y ahí empecé mi camino formativo en el arte.

Al iniciar la universidad, convencida de que tenía las habilidades, decidí ingresar a la carrera de Artes Plásticas con énfasis en Pintura; la idea era convertirme en una artista. Frente a esta aspiración ingenua, hoy surgen las interrogantes: ¿es posible aprender o enseñar a ser artista? ¿qué se enseña o se aprende en una escuela de arte? ¿se requiere de un don para ser artista?

En retrospectiva de la etapa universitaria, rescato varias situaciones, pues, a partir de ellas, puedo trazar una ruta de ese para qué se educa, qué se enseña y qué se aprende en la Educación Artística.

Uno de los hechos que me interesa rescatar es el filtro por el que pasa cualquier persona que quiere ingresar a estudiar artes: la prueba de habilidad. Cuando decidí ingresar a la carrera de Pintura en la Universidad de Costa Rica, en el año 2003, se debía cumplir con este requisito de ingreso. La prueba se dividía en cuatro diferentes etapas diagnósticas: dibujo a copia, dibujo creativo, collage y modelado. Este primer filtro -en teoría- determinaba si era apta(o), o no, para estudiar una carrera de artes. En este punto, es necesario mencionar que la persona postulada que realizaba este prediagnóstico no tenía claro qué se le evaluaba en la prueba, ni tampoco bajo qué criterios era evaluada. Frente a este hecho, me parece oportuno recurrir a la siguiente cita de Camnitzer (2007a) que expresa muy bien lo que estos filtros representan en un sistema educativo formal:

Tenemos por un lado la posibilidad de que el "talento artístico" sea una condición dada a unos pocos, no importa si como asunto genético, por la gracia de Dios, o por el uso de vitaminas. Cuando se habla de la posibilidad de enseñar arte, realmente se habla de la posibilidad de pasar "talento artístico" de una persona (profesor) a otra (alumno). Si esa posibilidad no existe, la escuela se convierte en un filtro para descartar aquellos sin talento y destilar aquellos elegidos que merecerán el título de artistas. (pp. 44-45) 
Con base en esta cita, es posible inferir que, desde el ingreso a la Escuela de Artes, se posiciona la idea del innatismo, de traer o no -de nacimiento- el talento artístico; de no tener esta condición, parece que la idea de aprender arte se vuelve imposible. Esta idea de que el talento pertenece a algunos individuos, posiciona a la academia de arte como una instancia excluyente y se refuerza la idea de que el arte es una habilidad de solo pocas personas: quienes lo producen, quienes lo estudian y quienes lo pueden comprar.

Otro hecho que me interesa resaltar, desde mi experiencia, parte de la conformación del currículo oficial, pues el plan de estudios del bachillerato estaba -y aún lo está- atravesado por dos sólidos pilares: el dibujo y de diseño, herencia de la academia europea importada en el siglo XIX, como bien lo refiere Sánchez (2016):

Esta vertiente academicista que define a la Escuela en sus inicios tiene actualmente una fuerte influencia, pues 116 años después, el Dibujo y el Diseño siguen siendo pilares fundamentales sobre los que se desarrolla el planteamiento curricular actual. (p. 6)

De estos dos pilares se deriva el primer "choque" al que tuve que enfrentarme como estudiante de arte: aprender a dibujar. Los primeros cursos de dibujo se basaban en dibujo estructural y lineal. Este método de aprender dibujo consiste en dibujar un objeto complejo, descomponiéndolo en figuras geométricas más simples -cubo, prisma, cilindro, esfera, entre otras-. Esta manera de aprender dibujo, sin duda, es una forma de dibujar muy diferente a la que estaba acostumbrada, pues apela a la racionalidad, más que a la intuición y la percepción. Este método didáctico remite, a la segunda y tercera regla del método cartesiano:

La segunda era dividir cada problema en tantas pequeñas partes como fuese posible y necesario para resolverlo mejor.

La tercera conducir con orden mis pensamientos, esperando por los objetos más sencillos y más fáciles de conocer, para ir ascendiendo poco a poco, como por peldaños, hasta el conocimiento de los más complejos: y suponiendo un orden también entre aquellos en que los unos no proceden naturalmente a los otros. (Munari, 1981, p. 6) 
De esta racionalidad en el dibujo, surgieron conceptos abstractos, tales como: proporción, calidad de línea, volumetría, planimetría, entre otros. Posteriormente, en los cursos de figura humana salieron a luz, conceptos como: cánones, anatomía, perspectiva, escorzo, etc. Nuevamente, otro rastro de la modernidad europea: los cánones de representación estudiados no eran los de la figura anatómica latinoamericana, sino cánones griegos, egipcios, y renacentistas basados en ideales de belleza y perfección. Este ideal occidental de belleza responde a idealizaciones gestadas desde la antigua Grecia, tal como afirma Umberto Eco:

En contra de lo que se creerá más tarde, la escultura griega no idealiza un cuerpo abstracto, sino que busca más bien una belleza ideal efectuando una síntesis de cuerpos vivos en la que expresa una belleza psicofísica que armoniza alma y cuerpo, o bien la belleza de las formas y la bondad del espíritu: es el ideal de Kalokagathía (...). (2004, p. 45)

De este modo, la representación griega de la figura humana no solamente responde a cuestiones de medidas meramente anatómicas, sino también a una manera de visión de mundo, en donde la belleza está ligada a las ideas de hombre virtuoso del pensamiento filosófico griego.

Ligado a esta visión de mundo occidental, aprendí a dibujar de la manera correcta, copiando réplicas en yeso de las esculturas clásicas griegas y romanas. En los cursos de la especialidad, aprendí a pintar al óleo y acuarela, naturalezas muertas -al mejor estilo del Barroco europeo- escenas pictóricas que emulaban estampas del Rococó, Neoclásico o el Romanticismo. Aprendí además a crear reproducciones de los grandes maestros europeos.

Así las cosas, dentro del currículum oficial también, se encontraban los cursos de Historia del Arte que incluían el desarrollo del arte desde la antigüedad clásica -Egipto, Creta, Roma, Babilonia- el Arte Medieval, el Renacimiento, el periodo Neoclásico, el Romanticismo, hasta movimientos más modernos del arte; en fin, toda la historia del arte universal. Sucesivamente, a lo largo de toda la carrera fui encontrando rescoldos de un camino que conduce a la fuerte herencia europeizante que define la concepción de qué es arte y qué no, y marca la visión del arte que se enseña en la universidad. 
Al mirar hacia atrás, puedo notar grandes ausencias en la formación que dejan a su paso las preguntas: ¿qué pasaba con las grandes maestras del arte? ¿qué sucede con el arte que no-europeo? ¿solo en Europa se produce arte?, ¿por qué los cursos que buscaban una alternativa al eurocentrismo eran optativos y no formaban parte de los cursos obligatorios?, ¿acaso es optativo conocer nuestras raíces? Estas ausencias forman parte, de lo que Acaso (2009) llama currículum ausente que refiere a todo aquello "que aprendemos de lo que no nos enseñan" (p. 61). De este modo, el currículo oficial lleva implícito, un mensaje que continúa posicionando una visión de mundo dominante y niega todo aquello que no se apega a la norma, "Y es que lo ausente, por las razones que sean (porque tanto consciente como inconscientemente se provoca la ausencia de algo), tiene mucho más peso que lo presente" (Acaso, 2009, p. 58).

Relacionado con la experiencia educativa, hoy puedo afirmar que con cada curso que ganaba perdía parte de mi propia identidad, capacidad creativa y espontaneidad naif ${ }^{3}$, pues antes de dibujar, pintar, o incluso de pensar, saltaban a mi mente todos los prejuicios de lo debe ser una buena artista, apegada a los ideales de lo que me enseñaron; en definitiva, negaba mi propia identidad como mujer artista latinoamericana. A lo largo de toda mi formación, aprendía cada vez más de lo que es el arte, pero desconocía cómo ser una artista en Costa Rica, hecho que enfrenté con más dureza al terminar la carrera.

Al finalizar una carrera de arte, cada estudiante, como bien lo afirma Camnitzer (2007a), inicia un proceso de "desaprendizaje mucho más duro y penoso que el del aprendizaje por el cual acaba de pasar" (p. 40). Esto debido a que, la persona que cree que sabe todo lo que necesita saber para ser artista, se da cuenta de que no sabe qué hacer en su contexto, en un país donde el arte es bello y mimético, sin lugar para lo desgarrador o transgresor.

Toda esta experiencia, no pretende ser solo un relato autobiográfico, sino que busca enmarcar la vivencia de lo que representa ser una estudiante de arte, graduarse de una carrera de arte, cuyo currículo no enseña a ser artista, ni a enseña sobre el arte. Enseña técnica, historia y una manera de representar y ver el mundo, desde una óptica hegemónica: la eurocéntrica y patriarcal.

3 Según el Diccionario de la Real Academia Española el concepto naif se refiere al arte o de una obra artística: Que se caracteriza por reflejar la realidad con deliberada ingenuidad, aparentemente infantil, y con poesía y simplicidad. 


\section{La necesidad de articular la pedagogía y el currículo: La ense- ñanza de las artes plásticas}

A partir de la experiencia articulada anteriormente, vale la pena analizar la relación que se da entre el para qué se educa y el qué se enseña, de un proyecto educativo como lo es una carrera universitaria. Pensar el para qué desde la Pedagogía implica reflexionar sobre cuál es el objetivo social que se desea conseguir con la educación que se ofrece desde un determinado campo del saber. Mientras que cavilar acerca de los contenidos o el currículum lleva a la necesidad de congruencia con esa finalidad.

Respecto a la pedagogía, se retoma el concepto de paideia de la Grecia antigua, pues, como se mencionó anteriormente, la experiencia a la que se hace referencia se enmarca en una universidad pública, que desde su estatuto orgánico se posiciona en una visión humanista. Este antecedente implica que la formación brindada en esta institución es concebida desde un ideal en el que se forma académica y profesionalmente para la vida y no solo para insertarse en un sistema productivo económico.

La paideia contribuía a "la transformación del hombre [de la persona] hacia la conquista de un hombre [una persona] libre" (Quiceno, 2014, p. 28). Es decir, la pedagogía estaba vinculada a la emancipación de la persona, a través de la educación y al ejercicio responsable de la libertad. La educación estaba enfocada en el objetivo de que la persona fuera consciente de la necesidad de cultivar la virtud y emanciparse, pues cada individuo es virtuoso en medida en que se conoce a sí mismo. Esta idea de la pedagogía como un medio para la emancipación se refiere específicamente a aquella que conduce a la liberación.

Con respecto al currículum y su relación con la Pedagogía, resulta importante señalar que este no debería pensarse aislado de la finalidad pedagógica del proyecto educativo, pues pierde el sentido transformador y se convierte en un conjunto de conocimientos para transmitir, el cual puede correr el riesgo de perder claridad en cuanto al objetivo social que se persigue. Cuando se piensa el currículo desde la reflexión crítica que implica una pedagogía emancipadora, se posiciona desde un ideal de educación para. Ese para puede ser para cumplir un rol específico en la sociedad, o para cultivar una mejor versión del ser y alcanzar la virtud, o incluso ambas, como sucede en el caso de la paideia. 
Así, posicionar pedagógicamente el currículo desde una postura crítica lo dota de un potencial transformador, se convierte en un medio para alcanzar un tipo de sociedad a través de él y deja de ser un fin en sí mismo. Por consiguiente, ya no se enseña, por enseñar; sino que, la enseñanza se hace con un sentido humanista, con convicción, responsabilidad y plena conciencia de lo que implica la educación en una sociedad.

Ahora bien, frente a este ideal de emancipación, es posible encontrar el término currículum, cuyo origen podría parecernos antagónico a la búsqueda de la liberación, pues en un principio fue pensado como un dispositivo de poder para el sometimiento, el cual está ligado a la institucionalización de la Educación formal como medio de preparación de las personas para el trabajo, como bien lo afirma Díaz-Barriga (2009):

El surgimiento del campo del currículo a principios del siglo XX, cubría la necesidad de atender a los problemas que afrontaba la enseñanza en el contexto del sistema escolar. A su vez, estuvo signado por el surgimiento de la industrialización de esos años. (p. 5)

Ante tal origen, se genera la disyuntiva ¿cómo conciliar la idea de una pedagogía emancipadora con un currículum establecido desde el interés de someter?, ¿cuál sería un currículum que nos ayude a emanciparnos?, ¿cómo lograr esta emancipación desde la misma forma en que se plantea el currículo?

Tratando de buscar una respuesta a tales interrogantes, vale la pena mencionar qué se entiende por currículum. Para esto, se parte de la noción que plantea De Alba (2016):

El currículum es una propuesta cultural y político-educativa que se constituye en un horizonte ontológico semiótico (hos) o cultura, a partir de la sobredeterminación (curricular) de una compleja síntesis cultural y político educativa, como un dispositivo educativo de poder y saber acorde con el mainstream de la configuración político cultural y educativa o el sistema en el cual se inscribe dicho dispositivo. (p. 196)

Esta definición que aporta De Alba (2016) permite: 
1. Reconocer el currículum como una propuesta política educativa; es política en tanto, se reconoce que su diseño está a cargo de un grupo- generalmente de personas académicas- que deciden qué conocimientos deben enseñarse, de acuerdo con una intencionalidad y en respuesta a un contexto determinado. De ahí también el término horizonte ontológico semiótico.

2. Ser un dispositivo de poder, pues, desde su conformación, se establece roles y juegos de poder que determinan las decisiones, ya sea por medio de consensos o imposiciones. Así mismo, se convierte en dispositivo de poder, pues se encuentra al servicio del mainstream o tendencia dominante que decide qué se debe enseñar y para qué.

Tomando en consideración lo anterior, conviene preguntarse qué papel juegan los y las estudiantes como principales beneficiados o perjudicados de este currículum, más aún si pensamos nuevamente en las carreras de Artes Plásticas en la Universidad de Costa Rica. El pensum de estudios de estas carreras ha sido producto de lo que la comunidad académica ha escogido como el conjunto de conocimientos, habilidades, valores y actitudes que conforman la formación académica-profesional para responder a un objetivo, el de formar artistas o personas profesionales en arte.

En cuanto a este objetivo, resulta adecuado apelar a la experiencia personal, pues, aunque al ingresar a la carrera, mi objetivo era estudiar arte y convertirme en una artista, la formación como tal, pareciera no tener claro sobre qué es lo que se busca. Con base en mi experiencia, es posible afirmar que en el cuerpo docente no existía consenso, pues, mientras algunos docentes decían que solo una pequeña parte de la población estudiantil de la carrera serían artistas -nuevamente la idea del talento dado a unos pocos- otros enseñaban técnica y otros hablaban de la importancia de saber $x$ o $y$ conocimiento que, como futuros artistas, necesitaríamos. Esta situación será problematizada en el siguiente apartado.

\section{V. ¿Artistas o personas expertas en la técnica?}

La interrogante que enuncia este apartado pretende problematizar la claridad -o la ausencia de esta- en cuanto a lo que se desea lograr a través de los contenidos y la enseñanza que se brinda en las carreras 
de Artes Plásticas de la UCR. Es decir, se presenta una situación problemática de índole pedagógico y curricular.

El autor Luis Camnitzer en su artículo ¿Es posible la enseñanza del arte? plantea, una situación bastante particular en torno a la educación artística que nos permite comprender el nexo que tiene la técnica y lo que hace quien es artista:

$\mathrm{Al}$ artista se le pregunta: “¿Usted qué hace?” Y el artista responde: "Yo pinto al óleo". A una pregunta que plantea un "qué", se le contesta un "cómo". Lo que bajo otras circunstancias se le percibiría como un diálogo de sordos, o mejor, un diálogo que no se cumple, en este caso es aceptado por ambas partes como un intercambio satisfactorio. El interrogador cree que sabe más de arte que el artista. El artista cree que con la información técnica justifica su actividad. (Camnitzer, 2007a, p. 40)

Esta confusión, según Camnitzer (2007a), es la que hace que los planes de estudios se organicen en cursos de técnica, como, por ejemplo, Pintura I y Pintura II, pretendiendo enseñar arte. Si bien la técnica es el medio, no el fin, entonces ¿cómo es que se pretende formar artistas cuando una gran parte del currículum está pensado en enseñar técnica? Si a esta situación le sumamos el hecho -que se mencionó con anterioridad- de que muchos de los métodos didácticos utilizados para la enseñanza de la técnica se basan en la copia de los ejercicios planteados por los grandes maestros (hombres europeos) merece la pena detenerse y cuestionar: ¿dónde queda el arte?, ¿cómo se logra hacer el salto de la técnica al arte? Aquí precisamente es donde, desde mi percepción, se pierde el objetivo, en cuanto se sobrevalora el cómo.

El ejercicio de copia que, como ejercicio didáctico, pretende desarrollar la habilidad de la observación, se convierte en el objetivo, pues entre más se parezca a la realidad, mejor artista se es. Entonces, entre líneas, el currículum oculto enseña a aprender a dibujar como Durero, a pintar como Rembrandt, esculpir como Bernini, a hacer arte conceptual, imitando ejercicios de artistas conceptuales como Duchamp y, de esta forma, se recrean -malas o buenas- copias, pero no se aprende a pensar, crear, ni expresarse a través de autodescubrimiento por medio del arte.

Según Camnitzer (2007a), "la educación artística del estudiante (...) debiera entonces ayudar al estudiante a definir qué es lo que 
quiere expresar para recién entonces buscar los mecanismos técnicos referentes a cómo expresarlo" (p. 49) y no es a través de la imitación que esto se logra.

La situación descrita, aunque parezca satírica, encarna la realidad de lo que pasa en los salones de clase, debido a una falta de claridad en el objetivo pedagógico de la formación que se refleja en el currículum y perfil de egreso de la carrera. Esto se evidencia en los mismos planes de estudio. Por ejemplo, el actual plan de estudio de la carrera de Diseño Pictórico, dentro de los objetivos, establece como objetivo general: "Formar un profesional en pintura. Un investigador visual multisensorial en su área, iconográfico, crítico, con dominio técnico y formal, capaz de trabajar interdisciplinariamente al identificarse con su medio" (Vicerrectoría de Docencia, 2007).

Con base en lo anterior, está claro que el objetivo de la carrera es dotar a la persona estudiante de conocimientos técnicos que le lleven a convertirse en una persona profesional en pintura. Ahora bien icon qué fin se enseñan las técnicas? ¿qué papel juega esa persona en la sociedad? ¿qué hace un investigador visual multisensorial?, ¿es un(a) investigador(a)? ¿es un pintor(a)? ¿será un(a) docente?

Referente al proceso de enseñanza de la técnica dentro de las Artes Plásticas, es necesario hacer mención a lo que indica Gaillot (2013):

La verdadera cuestión no juzgar el nivel de direccionalidad del profesor [persona docente], sino saber si el alumno de AP [Artes Plásticas] está situado dentro de una actividad de ejecución o de una actividad de búsqueda, así como dentro de una postura interrogativa particular. (p. 24)

Lo anterior, coloca la discusión en otro escenario, pues lleva a pensar el rol de la persona docente en el proceso de enseñanza en cuanto se debe prestar atención a la distinción de las necesidades de aprendizaje y los intereses temáticos de la población estudiantil.

La enseñanza de arte se aleja del propósito de incentivar a la persona estudiante a que descubra su propia identidad creativa y que sea él o ella quien decida cómo desea hacerlo, pues se le condiciona primero a aprender técnicas de representación que le desmotivan y hacen perder el gusto por lo que hace, al hacer creer a la persona estudiante que de no lograr la precisión técnica -qué tanto se busca en 
la escuela de arte- le será imposible llegar a ser buen(a) artista, por lo cual su creatividad se ve coartada.

Asimismo, se enseña a copiar recetas ajenas, pero no a buscar soluciones propias a los problemas, ni a los retos conceptuales y estéticos a los que se enfrenta en su formación, hecho que ocasiona que "la formación técnico-artesanal en esta etapa esencialmente pre-estética usurparía la actividad del cuestionamiento y lograría no solamente una ejecución correcta de soluciones ajenas, generalmente ya estereotipada" (Camnitzer, 2007a, p. 48).

Ante tal realidad, se retoma la idea de la necesidad de un proceso formativo en el arte que apele a la emancipación de la persona estudiante, más que al sometimiento, la repetición y perfección en la ejecución. En la actualidad existen los medios (video tutoriales para el aprendizaje y el perfeccionamiento de la técnica, por ejemplo), por lo que, de ser el perfeccionamiento de la técnica el único propósito de la formación, esta se podría aprender de forma autodidacta, sin necesidad de ir a una universidad:

Hoy no podemos negarle al estudiante la formación técnica por cual viene a nosotros. Pero si podemos ir más allá de su pedido y cuestionar la motivación del pedido y las formas que tradicionalmente se utilizan para responderle. (Camnitzer, 2007b, p. 81)

Por este motivo, se debe buscar un balance en el proceso con la finalidad de que, sin dejar de lado el aprendizaje de la técnica, la creación no sea supeditada a la destreza técnica, sino que esta sea un medio más para lograr transmitir un mensaje propio.

\section{Dibujar nuevos horizontes: Una propuesta pedagógica para la emancipación en las artes plásticas}

Planteada la problemática, lo siguiente es pensar en una propuesta que pueda ayudar a tener claridad en cuanto a la intencionalidad pedagógica de la formación académica profesional de las carreras de Artes Plásticas de la UCR, pues, como se mencionó, en la actualidad la Unidad Académica está en un proceso de revisión curricular. Esto representa una oportunidad para analizar, desde la articulación de pedagogía y el currículum, la posibilidad de transformación de la formación universitaria que actualmente se brinda. 
Proponer una alternativa pedagógica para la emancipación coloca al estudiantado en otro nivel, pues pretende involucrarlo en su propio proceso de aprendizaje; de manera tal que sean los y las estudiantes quienes propongan qué quieren aprender y cómo desean hacerlo y la mejor manera de descubrir su potencial creador y transformador a través de la educación.

Partir de una pedagogía para la emancipación implica, también, un cambio que abarca no solo la estructura curricular, sino también la docencia, pues requiere de flexibilidad de la persona docente para dejar de lado el control y la angustia derivados de la presión que conlleva la obligación de abarcar los contenidos establecidos y, además, tener la disposición para guiar al discente en un proceso en que ambas partes se verán retadas y enriquecidas.

Asimismo, desde mi experiencia como asesora curricular, al imaginar un currículo para la emancipación, no es posible evitar pensar en el desplome de la idea de un currículum preestablecido, pues un plan de estudios desde esta visión define lo que se debe aprender y no lo que necesito y quiero aprender. Proponer un currículo para la emancipación exige:

1. Que los planes de estudios reflejen intencionalidades pedagógicas y no recetas inflexibles copiadas de otros contextos que indiquen, paso a paso, lo que la persona docente debe enseñar, sin posibilidad de variar, adaptar o innovar. Esta idea de currículum implica, como bien lo indica Acaso (2012):

Entender el currículum como un sistema de representación nos lleva a plantearnos algo de enorme importancia y es que, como profesoras, tenemos que abrir la puerta a la idea de que nosotras somos las responsables de nuestros currículums y, por ende, (...) somos las que elegimos los contenidos, las que organizamos la secuencia y no con otra y las que establecemos la arquitectura mediante la que ese currículum sucederá. (p. 55)

Es decir, se busca que la persona docente retome la potestad de pensar el currículum como algo vivo, de lo cual es responsable, pues su desarrollo se hace posible desde de su criterio y experiencia. Esto significa dejar de pensar el currículum como una camisa de fuerza y 
dimensionarlo como un apoyo al estudiantado, en el proceso de autodescubrimiento que implica aprender.

2. Que los procesos de diseño curricular sean procesos participativos, en los que la población estudiantil sea escuchada y tenga poder de decisión. A lo largo de mi experiencia como asesora he escuchado docentes afirmar que los y las estudiantes no tienen criterio de lo que se les enseña, pero esta idea es totalmente falsa, pues nadie sabe más del currículum y de pedagogía que el estudiantado. Ellos son quienes más capacidad tienen para saber cuándo un aspecto en la formación, -(ya sea el currículo, didáctica, evaluación, entre otros)está bien o no. En la academia, para mejorar se debe aprender a tener la humildad para escuchar y tener muy claro que no es posible ser docente sin los y las estudiantes.

3. El currículum de la educación artística para la transformación debe salirse de la burbuja europea, aprender a valorar los conocimientos generados desde su propio contexto, así como nutrirse de otras latitudes. El conocimiento también debe ser gestado desde la periferia o desde el Sur -como lo llama Enrique Dussel-. Aprender arte, diseño, dibujo e historia, desde nuestras realidades, ya que "las culturas poscoloniales deben efectivamente descolonizarse, pero para ello deben comenzar por autovalorarse" (Dussel, 2015, p. 285). Aprender a observar no implica solamente copiar lo que otros hicieron, sino también aprender a observar lo que existe en nuestro propio contexto, implica incluir a las minorías, aprender a leer los mensajes a través de una semiótica del arte más inclusiva y menos hegemónica.

En cuanto a la docencia, como medio para la emancipación, se desplaza la figura de docente como centro, como dueña del conocimiento, y se reconoce que el proceso de enseñanza y aprendizaje es un acto recíproco y multidireccional, en el que tanto docente como estudiante enseñan y aprenden.

Para esta transformación, el primer acto emancipatorio se produce al reconocer que el aprendizaje es un acto de voluntad, pues nadie aprende lo que le enseñan, sino aquello que desea aprender. Como bien lo afirma Jacques Rancière en El maestro ignorante: "se podía aprender solo y sin maestro explicador cuando se quería, o por la tensión del propio deseo o por la dificultad de la situación" (Rancière, 2003, p. 11). 
Esta postura arrebata el poder a la institución, al docente o al currículo, pues el poder del aprendizaje lo tiene quien desea aprender.

Recuerdo que en mis años de experiencia muchas veces sentía que el aprendizaje lo lograba de forma autodidacta, sin certeza de estarlo haciendo bien, pues la persona docente participaba al mínimo.

El hecho que encarna dicha experiencia recae en el hecho de que a nivel social no se enseña a confiar en la inteligencia y capacidad personal. La educación institucionalizada ha ocasionado que las personas se hayan convertido en seres dependientes, despojándolas de la responsabilidad del propio aprendizaje. De este modo, la educación se convierte en atontamiento.

Existe atontamiento allí donde una inteligencia está subordinada a otra inteligencia El hombre -y el niño en particular- puede necesitar un maestro cuando su voluntad no es lo bastante fuerte para ponerlo y mantenerlo en su trayecto. Pero esta sujeción es puramente de voluntad a voluntad. (Rancière, 2003, p. 11)

En relación con lo propuesto, se debe tener en cuenta que los cambios no son fenómenos a corto plazo, sino un proceso paulatino que requiere de ajustes. Posiblemente, al referirnos a la educación superior, las resistencias no solo vengan del cuerpo docente, o de la estructura institucional, sino también, del estudiantado, condicionado a un estilo de aprendizaje atontador ${ }^{4}$. Pero como lo indica Rancière (2003), "se puede enseñar lo que se ignora, si se emancipa al alumno, es decir, si se le obliga a usar su propia inteligencia" (p. 12). Resulta parte de la emancipación el hecho de asumir la responsabilidad que implica hacerse cargo de sí mismo y asumir las consecuencias de las decisiones y confiar de que la ignorancia también es parte del aprendizaje, pues es un estado necesario para aprender.

La propuesta de negociar el currículum, la didáctica y otros elementos vinculados al proceso educativo, sin duda, puede resultar retadora, máxime en un ambiente educativo en el que muchas veces el personal docente no tiene formación pedagógica adecuada y su praxis,

4 El término "atontador" es utilizado por el autor Jacques Rancière, en el libro "El maestro ignorante" para referirse al tipo de educación en la que no se permite a la persona estudiante aprender por sí misma, descubrir y emanciparse. 
por ende, se encuentra basada en la experiencia y la repetición de modelos con los que aprendieron durante la época de estudiantes:

El ¿qué? se enseña se colma con contenidos programáticos usuales y el ¿cómo? queda librado al buen sentido pedagógico del profesor, que será más o menos fundamentado de acuerdo a la formación docente que haya recibido y/o a las diversas experiencias que haya recogido en su trabajo de enseñante y, en especial, a las que haya acumulado en su etapa de estudiante". (Cerletti, 2009, p. 80)

Abrirse a la posibilidad de pensar y de pensarse desde otro ángulo que no es el tradicionalmente impuesto desde el control y el poder, resulta también liberador: "Para emancipar a un ignorante, es necesario y suficiente con estar uno mismo emancipado, es decir, con ser consciente del verdadero poder del espíritu humano" (Rancière, 2003 p. 12).

La emancipación en enseñanza de las Artes Plásticas deviene de otras relaciones pedagógicas que permiten romper esquemas heredados del siglo XIX. La educación artística debe abandonar el estereotipo del artista como un elegido y abandonar también la perpetuación de este cliché, por medio de los filtros que hacen de la educación un decantador de talento.

Asimismo, se debe dejar de lado la idea de que el arte es asunto de la élite, porque más allá de clases sociales o de un grupo dominante que determine que es o no es arte, o quién lo puede producir, enseñar o aprender, el arte es expresión y, por lo tanto, la capacidad de expresarse o identificarse con lo que otra persona expresó, es una característica natural del ser humano.

\section{Reflexiones finales}

Para finalizar, tomando como base lo desarrollado en este ensayo, es preciso resaltar la necesidad de que las unidades académicas replanteen los puntos de partida desde los que se construyen las propuestas educativas. Se requiere encauzar la reflexión respecto al tipo de educación que se ejerce, en concordancia con las bases en las que se fundamenta la respectiva institución. De este modo, si se parte de una institución humanista, las propuestas educativas deben fomentar valores humanistas como la conciencia social y la criticidad, con el objetivo 
de desencadenar procesos de transformación social y, desde ahí, posicionar el tipo de pedagogía y la intencionalidad del para qué educar.

La experiencia que aquí se planteó hace referencia al caso específico de la formación en el área de las artes plásticas en Universidad de Costa Rica, pero resulta aplicable a cualquier campo de conocimiento o cualquier carrera en educación superior, en las que el apego a formas de enseñanza y posturas arrastradas desde siglos anteriores no permiten un viraje necesario en la manera de pensar y repensar el quehacer de la docencia. De este modo, se debe entender que muchos parámetros que representaron un método didáctico exitoso en Europa en los siglos anteriores, no necesariamente resultan exitosos como mecanismos de enseñanza en la Latinoamérica del siglo XXI.

La oportunidad que representa imaginar otros mundos posibles, desde la pedagogía universitaria, surge de la reflexión y del contacto con otros grandes pensadores y pensadoras que han buscado cuestionar el statu quo. Gracias también a profesionales en pedagogía que han sabido reconocer que para enseñar o aprender no es necesario imponer, sino respetar.

Para que esto suceda, se propone que en los procesos de diseño curricular sean consideradas todas las partes involucradas, pero muy en especial a la población estudiantil y al cuerpo docente; para esto, el currículo debe dejar de ser un término abstracto y desconocido para convertirse en un proceso de participación y consensos. Asimismo, si se desea transformar la docencia, es debido perder el temor a cometer errores en el campo docente.

El arte es un campo complejo difícil de definir, debido a la posibilidad de caer en encasillamientos o reduccionismos; no obstante, queda evidenciado que este no necesariamente debe ser entendido como cuestión elitista incomprensible A partir de los propios referentes, las personas -indistintamente de que sean consideradas artistas o no- poseen la capacidad de crear y re-crear. Por tanto, una educación artística no debería estar sujeta meramente a la técnica o a la expresión, sino que debería estar enfocada en la creación de mecanismos y herramientas para reconstruir y transformar realidades. 


\section{Referencias}

Acaso, M. (2009). La educación artística no son manualidades. Nuevas prácticas en la enseñanza de las artes y la cultura visual. Catarata.

Acaso, M. (2012). Pedagogías invisibles. El espacio del aula como discurso. Catarata.

Camnitzer, L. (2007a). ¿Es posible la enseñanza del arte? En M. A. Bernal y F. González (Eds.), Antología de textos críticos 1979-2006. ArtNexus/Arte en Colombia (pp. 38-52). Ediciones Uniandes.

Camnitzer, L. (2007b). La definición restringida de arte. En M. A. Bernal y F. González (Eds.), Antología de textos críticos 1979-2006. ArtNexus/ Arte en Colombia (pp. 74-84). Ediciones Uniandes.

Cerletti, A. (2009). La enseñanza de la filosofía en perspectiva. Eudeba.

De Sousa, B. (2007). La universidad en el siglo XXI: Para una reforma democrática y emancipatoria de la universidad. CIDES-UMSA, ASDI y PLURAL EDITORES.

De Alba, A. (2016). Cultura y contornos sociales. Transversalidad en el currículum universitario. En A. De Alba y A. Casimiro (Coords.), Diálogos curriculares entre México y Brasil (pp. 195-210). IISUE.

Díaz-Barriga, Á. (2003). Currículum. Tensiones conceptuales y prácticas. Revista Electrónica de Investigación Educativa, 5(2), 1-14. http://redie.uabc.mx/vol5no2/contenido-diazbarriga.html

Dussel, E. (2015). Filosofias del sur. Descolonización y transmodernidad. Akal.

Eco, U. (2004). Historia de la belleza. Debolsillo.

Gaillot, B., A. (2013). Artes plásticas. Elementos de una didáctica crítica. ENAP- UNAM.

Martinez, J. (2015). Colonialidad e identidad en América Latina. Casa Editorial Analéctica.

Munari, B. (1981). Como nacen los objetos. Apuntes para una metodología proyectual. Editorial Gustavo Gilli.

Quiceno, H. (2014). Epistemología de la pedagogía. Ediciones Pedagogía y Educación.

Rancière, J. (2003). El maestro ignorante. Cinco lecciones hacia la emancipación intelectual. Laertes.

Sánchez, J. (2016). Arte y currículum: La Escuela de Artes Plásticas de la Universidad de Costa Rica (1897-2015). Revista Humanidades, 6(1), 1-40. https://revistas.ucr.ac.cr/index.php/humanidades/article/view/24963 
Saxe-Fernández, J. (2006). Globalización, poder y educación pública. Ensayos críticos. Asociación Espacio Crítico.

Universidad de Costa Rica. (1974). Estatuto Orgánico de la Universidad de Costa Rica. http://www.cu.ucr.ac.cr/normativ/estatuto_organico.pdf

Universidad de Costa Rica. (1995). Politicas y Normas Curriculares para la Actualización de Planes de Estudio. https://www.cea. ucr.ac.cr/images/desarrollocurricular/Politicas-normas-curriculares1.pdf

Vicerrectoría de Docencia. (2007). Resolución VD-R-8126-2007. Universidad de Costa Rica. 
